delegates from Germany, England, Austria, Denmark, Spain, France, Holland, Italy, Norway, Russia, and Switzerland; the United States and Japan were unrepresented. In all, seventeen chemical societies are affiliated to the international association, representing nearly 20,000 members. Much valuable assistance was received from $M$. Tassel and from M. Heger in arranging for the meetings.

It was agreed that the place of meeting for rgr 4 should be Paris, with M. Haller as president. The business done at the Brussels meeting was satisfactory; steps were taken to affiliate the committee on atomic weights; to unify the methods of abbreviating the names of journals; to secure publication of important memoirs which have appeared in one of the less known languages in English, French, or German; to open negotiations to diminish the multiplicity of abstracts, by cooperation among the various bodies which publish extracts; and some important resolutions dealing with nomenclature, and with symbols for physical constants, were adopted.

The need of such an association has now been amply shown. Much can be done to simplify methods, and, by cooperation, to diminish labour, and increase convenience. There is still much to be done, however, and the usefulness of the association will doubtless survive the period at which Monsieur Solvay's gift will be exhausted. The assembling of chemists from various nations, with free interchange of ideas, cannot fail to stimulate all working at the science of chemistry, and cannot fail to promote cordial international relations. "La Science est sans patrie!"

William Ramsay.

\section{HEALTH IN INDIA.}

T NDER the title, "A Modern Miracle," The Pioneer Mail of September 12 gives some striking figures of the improvement of health among the European troops in India-these figures being taken from the Army Medical Report for last year. With a strength of more than 7I, ood British troops in India, there were positively only 328 deaths during the year, equal to $4^{\cdot 62}$ per Iooo. This is really a remarkable achievement; and the smallness of the death-rate is not due in any way to an increase in the invaliding to England-as shown by the fact that the invaliding also fell markedly during the year to 6.68 per rooo, compared with 23 per rooo in 1892 . These are by far the lowest rates on record, and are comparable with the great decrease in the death-rate and the invaliding among non-native officials in West Africa, as disclosed by recent Colonial Office Reports.

Enteric fever, which was once such a terrible pest in India, has now decreased so much that there were only i 18 admissions to hospital for it among the whole British garrison. This is undoubtedly due partly to the very great care now exercised in dealing with potential carriers of the disease, both human carriers and flies, and also to anti-typhoid inoculation. Malaria also has shown a very marked decrease during the year, though, as The Pioneer Mail points out, this may possibly be partly due to the usual fluctuations in the prevalence of the disease caused by variations in climate. Cholera and plague have also diminished.

Those who are interested in the subject would do well to compare with this fine record a remarkable paper by Sir Charles Pardey Lukis, DirectorGeneral of the Indian Medical Service, in the October number of Science Progress, entitled "The Sanitary Awakening of India." Sir Pardey Lukis describes the whole position of sanitation in India, and also the very extensive advances which are now being made in the investigation of disease, and the practical application of preventive measures there. Since he has occupied his important post, energy has been redoubled in all these directions. The whole Indian Medical Service, and the Officers of the Royal Army Medical Corps now serving in India, must all be heartily congratulated for the splendid work which they are now doing. Of course, there are ideals still before us; but the old apathy which used to exist in many quarters seems now to be a thing of the past.

Vaccination in India is also doing extremely well. Nearly two million vaccinations were performed in the Bengal Presidency alone during I912-13, and the total number of deaths from smallpox in that Presidency during the year was only $0^{\circ} 2 \mathrm{I}$ per thousand of the population-a very good figure for a country where vaccination has been much opposed on account of "religious" scruples. The lanoline lymph, which I believe was originally invented by Colonel King, is principally responsible for this good state of affairs, and Colonel King is to be much congratulated upon it.

Ronald Ross.

\section{THE PROBLEM OF THE UNIVERSITY OF LONDON.}

SINCE the article in our issue of December I I - was written, further events of importance have taken place. We referred in that article to the proposal of the Higher Education Sub-Committee of the London County Council to recommend the London County Council to invite the Senate of the University of London to express approval of Somerset House as a place for the further development of the University. The recommendation in favour of this site was adopted by the Council at Tuesday's meeting, after discussion. The Council agreed, without a division, to an amendment proposing that, if the Government could not consent to the Somerset House suggestion, the Education Committee should be instructed to report on the proposal to establish the university on a site on the south bank of the river, "where it would form an important feature in the beautifying of London." This proposal has something to be said for it from the point of view of the improvement of 